\title{
Persepsi Mahasiswa Terhadap Kualitas Sistem, Kualitas Informasi, dan Kualitas Layanan Elearning UIN Walisongo (Studi Kasus Mata Kuliah Manajemen Sistem Informasi)
}

\author{
Syaiful Bakhri \\ Fakultas Ilmu Tarbiyah dan Keguruan, Universitas Islam Negeri Walisongo Semarang \\ syaifulbakhri@walisongo.ac.id
}

\begin{abstract}
This study aims to determine student perceptions of system quality, information quality, and service quality at UIN Walisongo Semarang e-learning. This research case study is in the information system management course, majoring in Islamic Education Management (MPI) at the Faculty of Tarbiyah and Teacher Training (FITK) UIN Walisongo Semarang. The method used is direct field observation and interviews with MPI students. The results of this study indicate that the quality of the e-learning system at UIN Walisongo makes it easier for students in the learning process. The quality of information at UIN Walisongo's e-learning provides information about lecture materials and assignments, while the quality of services at UIN Walisongo's e-learning has provided tutorial media in the form of videos and PDFs, as well as the availability of helpdesk services to assist students in using UIN Walisongo's elearning.
\end{abstract}

Keywords: system quality, information quality, service quality

\begin{abstract}
Abstrak
Penelitian ini bertujuan untuk mengetahui persepsi mahasiswa terhadap kualitas sistem, kualitas informasi, dan kualitas layanan pada elearning UIN Walisongo Semarang. Studi kasus penelitian ini pada mata kuliah manajemen sistem informasi jurusan Manajemen Pendidikan Islam (MPI) di Fakultas Ilmu Tarbiyah dan Keguruan (FITK) UIN Walisongo Semarang. Metode yang digunakan adalah observasi di lapangan secara langsung dan wawancara dengan mahasiswa MPI. Hasil penelitian ini menunjukkan bahwa kualitas sistem pada elearning UIN Walisongo, memudahkan mahasiswa dalam proses pembelajaran. kualitas informasi pada elearning UIN Walisongo memberikan informasi tentang materi dan tugas perkuliahan, sedangkan kualitas layanan pada elearning UIN Walisongo sudah disediakan media tutorial dalam bentuk video dan PDF, serta tersedianya layanan helpdesk untuk membantu mahasiswa dalam menggunakan elearning UIN Walisongo.
\end{abstract}

Keywords: kualitas sistem, kualitas informasi, kualitas layanan

ISSN 2715-0143 (online) ISSN 2714-9048 (print) http://journal.walisongo.ac.id/index.php/jit/index 


\section{PENDAHULUAN}

Perkembangan teknologi 4,0 semakin berkembang pesat dan bertransformasi membantu banyak lini kehidupan baik itu di bidang industri, internet of things, teknologi cloud dan big data, begitu pula pada bidang pendidikan. Salah satu perkembangan teknologi di bidang pendidikan pada era digital ini adalah elearning, elearning merupakan kegiatan belajar mengajar yang pada pelaksanaanya menggunakan teknologi informasi dan komunikasi (Chitra and Raj, 2018), pendapat yang lain mengatakan bahwa elearning meliputi pemanfaatan teknologi untuk membantu meningkatkan proses belajar mengajar (Al-Sammarraie et al., 2019). Melalui pemanfaatan teknologi informasi, penggunaan elearning menjadikan proses belajar mengajar menjadi lebih mudah dan fleksibel tanpa mengurangi nilai penting dalam belajar.

Penggunaan elearning $\mathrm{di}$ berbagai lini pendidikan kini sudah mulai banyak digunakan, begitu pula di UIN Walisongo Semarang. UIN Walisongo Semarang sudah menggunakan elearning dalam perkuliahannya dengan metode blended learning, blended learning merupakan penggabungan metode konvensional dan digital dengan menawarkan lingkungan belajar yang fleksibel, inklusif, dan efisien (Machumu, Ghasia and Musabila, 2018). Adapun kegiatan belajar mengajar blended learning yang dilakukan di UIN Walisongo Semarang diantaranya adalah melalui tatap muka dan secara daring menggunakan platform video conference, sedangkan absen, pengiriman materi, dan penugasan dengan menggunakan platform elearning moodle. Metode elearning dapat dilakukan dengan dua jenis yaitu metode sinkronisasi dan asinkronisasi, sinkronisasi mempunyai arti peserta didik dan guru online di waktu yang bersamaan, sedangkan asinkronisasi artinya peserta didik menggunakan elearning secara mandiri (Alla, 2013).

Elearning yang sudah digunakan di UIN Walisongo pada proses belajar mengajar diharapkan dapat meningkatkan prestasi akademik mahasiswa, karena penggunaannya lebih mudah dan fleksibel. Harapan tersebut dapat tercapai apabila elarning UIN Walisongo mempunyai kualitas sistem yang prima untuk mahasiswa sebagai pihak yang melaksanakan pembelajaran melalui elearning .

Metode yang digunakan untuk mengukur kualitas elearning adalah dengan menggunakan model DeLone dan McLean (DeLone and McLean, 2003) yang mana model tersebut digunakan untuk mengetahui kualitas informasi, kualitas sistem, dan kualitas layanan. Oleh karena itu, persepsi mahasiswa sebagai pengguna utama elearning di UIN Walisongo perlu diteliti sebagai bahan evaluasi kualitas elearning, kendala dan harapan elearning di UIN Walisongo Semarang.

\section{METODE PENELITIAN}

Metode yang digunakan pada penelitian ini adalah kualitatif deskriptif.. Adapun sampel yang digunakan pada penelitian ini adalah mahasiswa jurusan MPI di Fakultas Ilmu Tarbiyah dan Keguruan UIN Walisongo Semarang pada tahun ajaran 2019/2020 yang menggunakan elearning . 
Metode pengumpulan data yang digunakan adalah observasi dan wawancara. Data yang dikumpulkan pada penelitian ini meliputi jenis kelamin, platform elearning yang digunakan, aplikasi video conference sebagai media pendukung elearning , dan tingkat semester mahasiswa.

Salah satu metode yang digunakan untuk menganalisis kualitas sistem elearning adalah dengan menggunakan model DeLone and McLean yang dalam modelnya terdapat aspek kualitas informasi, kualitas sistem, kualitas layanan, Penggunaan, Kepausan Pengguna, dan Manfaat Bersih (DeLone and McLean, 2003). Pada penelitian akan difokuskan pada tiga aspek utama terkait kualitas sistem yaitu kualitas sistem, kualitas informasi, dan kualitas layanan. Data wawancara yang diperoleh dari penelitian ini adalah :

1. Antusiasme pembelajaran sistem informasi manajemen menggunakan elearning UIN Walisongo dilihat dari aspek kualitas sistem, kualitas informasi, dan kualitas layanan

2. Kendala dalam menggunakan elearning UIN Walisongo
3. Harapan mahasiswa terhadap fitur elearning UIN Walisongo

\section{PEMBAHASAN}

\section{Hasil Wawancara}

Berdasarkan hasil wawancara yang dikumpulkan sebagian besar mahasiswa menggunakan elearning UIN Walisongo sebagai media pembelajaran, setelah itu baru menggunakan platform google classroom. Mahasiswa juga menggunakan video conference sebagai media pendukung elearning yang diurutkan dari yang paling banyak digunakan yaitu aplikasi Zoom, Google Meet, Whatsapp, dan portal video conference UIN Walisongo yang dapat diakses di alamat vcon.walisongo.ac.id.

\section{Kualitas Sistem}

Kualitas sistem dapat diukur dari kemudahan dalam menggunakan sistem (Halonen et al., 2009). Berdasarkan pengamatan di lapangan, elearning UIN Walisongo menggunakan platform moodle yang secara umum fitur-fitur moodle dapat disesuaikan dengan kebutuhan, namun yang menjadikan keunggulan elearning UIN Walisongo adalah sebagai berikut : 


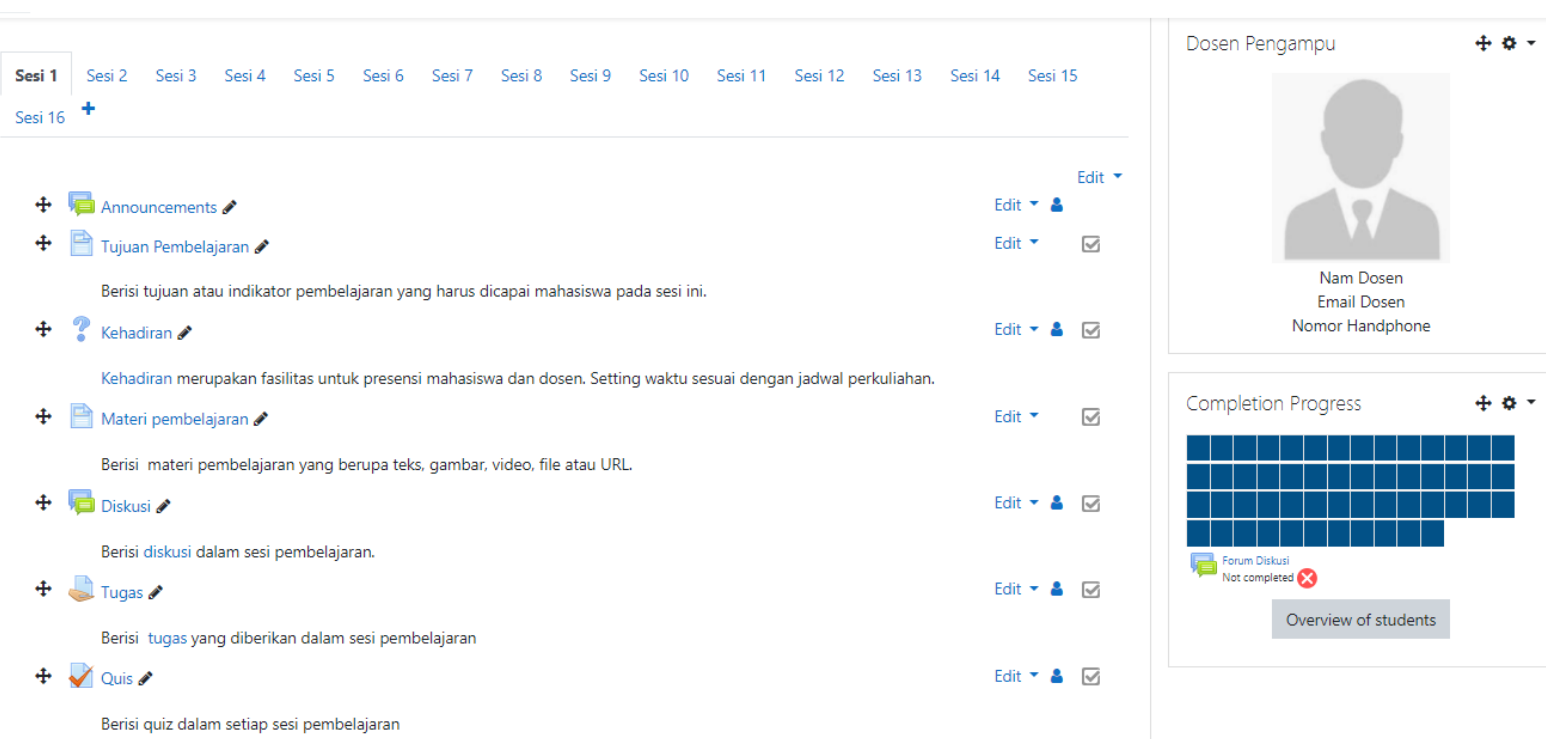

Gambar 1. Dashboard Elearning UIN Walisongo

1. Profil Dosen

Elearning UIN Walisongo terdapat menu untuk menampilkan foto profil dosen yang disertai dengan identitas dosen seperti nama dosen, email dosen, dan nomor handphone dihalaman dashboard.

\section{Completion Progress}

Pada bagian sebelah kanan setelah menu dosen terdapat completion progress, menu ini untuk menandai aktifitas apa saja yang sudah dikerjakan.

3. Sesi Pertemuan

Setiap pertemuan perkuliahan antara dosen dan mahasiswa dibuat dengan nama sesi, sesi ini terdiri dari pertemuan pertama sampai pertemuan terakhir yang dapat diklik melalui fitur tabulasi, sehingga memudahkan pengguna dalam memilih sesi perkuliahan.

4. Isi Sesi

Setiap isi sesi di dalamnya secara default terdiri dari tujuan pembelajaran, absensi kehadiran, materi pembelajaran, forum diskusi, penugasan, dan quiz. Isi sesi dibuat terstruktur dan sistematis seperti pada Gambar 1., tujuannya adalah untuk memudahkan mahasiswa dan dosen dalam menggunakan elearning .

Berdasarkan rekap kumpulan hasil wawancara dengan mahasiswa terkait kualitas sistem dari aspek kemudahan, mahasiswa menyatakan bahwa "elearning UIN Walisongo simpel dan praktis, lebih mudah digunakan, mudah diakses, mempermudah pelaksanaan belajar mengajar online, memaksimalkan penyerapan materi, membuat belajar lebih mudah dengan waktu yang fleksibel, mudah diakses dan ramah lingkungan, elearning menjadi semakin berkembang, dan menghemat banyak waktu". Pada bagian absensi menurut mahasiswa "memudahkan absen, model presensi dan pengumpulan tugas jadi mudah digunakan". Selain itu pada saat pengumpulan tugas, mahasiswa juga berpendapat bahwa elearning "mempermudah pengiriman tugas dan lebih efektif, memudahkan dalam melihat tugas dari dosen, mudah dalam melakukan download materi 
kuliah, dan elearning memberi kemudahan dalam forum diskusi", Observasi elearning UIN Walisongo ditinjau dari struktur navigasi menu, mahasiswa memberikan pendapat "lebih terstruktur dan mudah digunakan, tampilannya bagus dan tertata sehingga mudah dalam mengumpulkan tugas, fitur presensi materi kuliah dan tugas yang sudah terbagi sehingga mudah untuk dicari, dapat melihat tugas apa saja yang kita miliki, sistem pengumpulan tugas bisa tertata rapi, bisa melakukan download file, tersedia sistem upload file tugas, di elearning kita bisa buka forum diskusi dan dapat upload tugas, semua tugas materi kuliah dan absensi dalam satu aplikasi, forum diskusi sangat menarik dan mendapatkan materi pembelajaran sangat cepat, presensi lebih mudah dan pengumpulan deadline tugas lebih jelas, dapat mengirim tugas dengan aman dan bisa tepat waktu, penempatan materi/rps yang sistematis, elearning dapat dibuka setiap saat, menampung banyak dokumen file, sangat terstruktur dan memudahkan mengakses bahan pembelajaran". Persepsi yang diutarakan mahasiswa sesuai dengan hasil penelitian yang dilakukan oleh Hasan Al-Mamary, Shamsuddin and Aziati yang menyatakan bahwa kemudahan penggunaan dan kemudahan mempelajari menghasilkan perbaikan kualitas informasi (Hasan Al-Mamary, Shamsuddin and Aziati, 2014). Kualitas sistem juga dapat dilihat dari keandalan, mudah digunakan, kemampuan beradaptasi, dan waktu merespon (Seliana, Suroso and Yuliati, 2020).

\section{Kualitas Informasi}

Kualitas informasi dapat diketahui dari sistem tersebut dapat diakses, dan mempunyai keterbaruan (Al-Fraihat et al., 2020). Berdasarkan observasi elearning UIN Walisongo, dari sisi aksesabilitas, saat ini elearning UIN Walisongo dapat diakses melalui website yang dapat di akses di alamat URL (Uniform Resource Locator) https://elearning .walisongo.ac.id/ dan juga dapat diakses menggunakan aplikasi android. Sedangkan jika ditinjau dari sisi keterbaruan, elearning UIN Walisongo sudah melakukan install moodle versi terbaru yaitu versi moodle 3.10.1. Selain itu elearning UIN Walisongo sudah mengaktifkan notifikasi agar pada saat dosen submit konten maka mahasiswa mendapatkan pemberitahuan.

Dari hasil wawancara terkait kualitas informasi elearning UIN Walisongo dari sisi aksesibilitas, mahasiswa menyatakan "lebih cepat aksesnya, hemat dan mudah diakses, tidak terlalu ribet dan cukup efisien, bisa di akses 24 jam, mudah mengakses mata kuliah, jaringannya lumayan bagus tidak merepotkan dalam membuat tugas, memiliki fitur yang menarik ditambah lagi mudah dalam mengakses data". Sedangkan kualitas elearning UIN Walisongo dari sisi keterbaruan (update) mahasiswa berpendapat bahwa "elearning dapat memberikan informasi atau layanan materi yang disampaikan, memberikan informasi tentang materi dan tugas yang diberikan, terdapat pemberitahuan tugas, dan jadwal deadline tugas, dapat menampilkan mata kuliah dan tugas terkini, mengingatkan tugas yang harus di kerjakan, dan dapat pengingat secara 
pribadi jika ada tugas dari dosen". Selanjutnya, kualitas informasi dari elearning dapat diketahui dari sistem yang akurat, relevan, bermanfaat, dan mudah dipahami (Seliana, Suroso and Yuliati, 2020).

\section{Kualitas Layanan}

Kualitas layanan dapat diketahui apabila sistem tersebut dari ketersediaan staff dan menyediakan layanan bantuan (Al-Fraihat et al., 2020). Hasil observasi terkait kualitas layanan elearning UIN Walisongo, saat ini memiliki fitur-fitur pendukung pembelajaran daring diantaranya adalah video conference seperti aplikasi Zoom, Microsoft Teams, Google Meet, survey, wiki, glosarium, upload video, dan juga memiliki platform video conference internal yang dapat diakses di alamat http://vcon.walisongo.ac.id/. UIN Walisongo juga memiliki blog mahasiswa yang dapat diakses di alamat http://uinws.id.

Jika ditinjau dari sisi layanan bantuan, pihak pengembang/implementator yang dalam hal ini dilakukan oleh PTIPD (Pusat Teknologi Informasi dan Pangkalan Data) UIN Walisongo, sudah membuatkan berbagai tutorial dalam bentuk PDF, portal website yang dapat diakses di https://elearning

.walisongo.ac.id/elearning doc/, tutorial dalam bentuk video Youtube, dan portal pembelajaran yang di desain khusus untuk kursus online di alamat

https://welearn.walisongo.ac.id/.

Ketersediaan staff untuk membantu mahasiswa dan dosen dengan tersedianya layanan support helpdesk berbasis web yang dapat diakses melalui

https://helpdesk.walisongo.ac.id/

dan pusat bantuan melalui nomor WhatsApp Helpdesk yang dapat dihubungi dihari dan jam kerja kantor.

Hasil wawancara dengan mahasiswa terkait kualitas layanan, mereka berpendapat bahwa "dokumentasi penggunaan elearning sudah bagus dan terdapat tutorial dalam bentuk video yang sangat membantu, ketika mengalami kendala karena lupa password langsung menghubungi nomor Whatsapp helpdesk PTIPD".

\section{Kendala Penggunaan elearning}

Kendala dalam penggunaan elearning UIN Walisongo yang dirasakan oleh mahasiswa, mereka berpendapat bahwa:

- Akses yang terkadang lambat bahkan sering keluar sendiri walaupun saat jaringan internet lancer

- Bisa lebih ditingkatkan mode kehadiran seperti satu kali klik tanpa harus melakukan klik hadir lalu save my choice, serta peningkatan dalam hal mode pertemuan yang dibuat secara otomatis agar para dosen tidak susah dalam memantau kehadiran

- Ketika akan mengirim tugas di elearning agar kapasitas ruangannya lebih diperbesar

- Beberapa dosen di mata kuliah lain tidak menggunakan elearning saat absen, sehingga bagi para ketua kelas harus mengabsen manual. Seharusnya ada sosialisasi penggunaan elearning bagi para dosen

- Menu-menu yang ada dalam elearning serta sesi kehadiran 
lebih ditingkatkan, karena banyak dosen yang tidak melanjutkan membuka sesi-sesi pertemuan selanjutnya

- Tampilan pada forum diskusi agar lebih dipermudah

- Sosialisasi kepada dosen supaya banyak yang menggunakan elearning UIN Walisongo

- Penetapan waktu untuk absen dan terdapat tulisan waktunya, karena mahasiswa terkadang lupa absen

\section{Harapan Mahasiswa Terhadap Elearning}

Berikut ini adalah hal-hal yang menurut mahasiswa perlu adanya perbaikan, yaitu :

- Pelatihan dengan mendapatkan esertifikat

- Tingkatkan untuk jaringannya agar lebih nyaman dalam mengaksesnya

- Fitur seperti history yang mana dengan fitur tersebut kita dapat mengetahui aktivitas yang kita lakukan apa saja

- Pengingat saat h-1 pengumpulan tugas

- Tampilannya agar dibuat lebih menarik lagi

- Mengubah/membuat tampilannya dalam bentuk cover yang lebih menarik lagi, dan memberikan pemberitahuan tentang berita kampus

\section{Implikasi Manajerial}

Berdasarkan hasil penelitian yang dilakukan, jika dilihat dari aspek kualitas sistem, penggunaan elearning dapat mempermudah pelaksanaan belajar mengajar secara online, kemudahan dalam pengiriman tugas dan absensi, serta memaksimalkan penyerapan materi. Selanjutnya jika dilihat dari kualitas informasi, elearning memberi kemudahan dalam mengakses mata kuliah dan memberi update jika ada tugas dari dosen. Sedangkan jika ditinjau dari kualitas layanan, PTIPD UIN Walisongo selaku implementator sudah membuatkan berbagai media tutorial dan layanan pengaduan yang dapat diakses melalui website maupun helpdesk whatsapp.

Penggunaan elearning di UIN Walisongo jika dilihat dari kendala mahasiswa dalam penggunaan elearning, perlu untuk terus melakukan perbaikan agar elearning lebih stabil dan dapat dipergunakan secara maksimal. Oleh karena itu, dengan mempertimbangkan harapan mahasiswa terhadap elearning UIN Walisongo, oleh karena itu dari penelitian ini penulis merekomendasikan agar melakukan perbaikan secara menerus melalui :

- Meningkatkan performa server dan kecepatan jaringan internet

- Membuat agenda training untuk para dosen

- Membuat tim khusus untu menangani elearning UIN Walisongo

- Membuat manajemen proyek agar perkembangan status dan isu dapat dipantau

- Memperbanyak tutorial penggunaan elearning dalam bentuk pdf dan video

- Menyediakan layanan chat helpdesk untuk memudahkan komunikasi jika terjadi masalah pada elearning

- Membuat tampilan antarmuka elearning yang lebih menarik

- Dukungan dari manajemen dengan mengeluarkan kebijakan 
terkait penggunaan elearning secara menyeluruh

\section{KESIMPULAN}

Kesimpulan pada penelitian ini, elearning UIN Walisongo sudah berorientasi kepada kualitas yang dapat dilihat dari kualitas sistem, kualitas informasi, dan kualitas layanan. penelitian ini memberikan gambaran terkait persepsi mahasiswa terhadap elearning UIN Walisongo yang didalamnya meliputi antusias dalam menggunakan elearning, kendala, harapan, dan fitur untuk perbaikan dimasa yang akan datang. Melalui penelitian ini diharapkan dapat memberikan wawasan kepada pihak manajemen agar elearning UIN Walisongo semakin baik dan melakukan perbaikan secara terus menerus. 


\section{REFERENCES}

Al-Fraihat, D. et al. (2020) 'Evaluating E-learning systems success: An empirical study', Computers in Human Behavior, 102(August), pp. 67-86. doi: 10.1016/j.chb.2019.08.004.

Al-Sammarraie, N. A. et al. (2019) 'E-learning and students satisfaction - Case study MEDIU', International Journal of Recent Technology and Engineering, 7(6), pp. 220-225.

Alla, M. (2013) 'The Impact of System Quality in E-learning System', Journal of Computer Science and Information Technology, 1(2), pp. 14-23.

Chitra, A. P. and Raj, M. A. (2018) 'E-Learning', 3, pp. 11-13.

DeLone, W. H. and McLean, E. R. (2003) 'The DeLone and McLean model of information systems success: A ten-year update', Journal of Management Information Systems, 19(4), pp. 9-30. doi: 10.1080/07421222.2003.11045748.

Halonen, R. et al. (2009) 'DeLone \& McLean success model as a descriptive tool in evaluating a virtual learning environment', International Conference on Organizational Learning, Knowledge and Capabilities (OLKC 2009), (2008), p. 16. Available

at: http://scholar.google.com/scholar?hl=en\&btnG=Search\&q=intitle:DeLone+\& + McLean+success+model+as+a+descriptive+tool+in+evaluating+a+virtual+l earning+environment\#0\%5Cnhttp://scholar.google.com/scholar?hl=en\&btn $\mathrm{G}=$ Search\&q=intitle:DeLone+\&+McLean+Success+model.

Hasan Al-Mamary, Y., Shamsuddin, A. and Aziati, N. (2014) 'The Relationship between System Quality, Information Quality, and Organizational Performance', International Journal of Knowledge and Research in Management \& E-Commerce, 4(3), pp. 7-10.

Machumu, H., Ghasia, M. and Musabila, A. K. (2018) 'Blended Learning Activities in Blended Learning Environments: Experiences from Mzumbe University, Tanzania'.

Seliana, N., Suroso, A. I. and Yuliati, L. N. (2020) 'Evaluation of E-Learning Implementation in the University Using Delone and Mclean Success Model', Jurnal Aplikasi Manajemen, 18(2), pp. 345-352. doi: 10.21776/ub.jam.2020.018.02.15. 
Syaiful Bakhri ${ }^{1}$

This page intentionally left blank. 